\title{
The Impact of Employee Participation in the Planning Process on Organizational Effectiveness - The Case of Kosovo
}

Submitted 14/03/21, $1^{\text {st }}$ revision 12/04/21, $2^{\text {nd }}$ revision 28/04/21, accepted 20/05/21

Pajtim Rrustemi ${ }^{1}$, Blerina Bytyqi ${ }^{2}$, Alberta Tahiri $^{3}$, Idriz Kovaçi ${ }^{4}$

\begin{abstract}
:
Purpose: The main intention of this paper is to explain the impact of employee participation in the planning process on organizational effectiveness by illustrating such a phenomenon with research conducted in small and medium enterprises (SMEs) in Kosovo to prove once again that employee participation in organizational processes is essential to organizational success.

Design/Methodology/Approach: This paper applies the quantitative method to scientific research. A structured questionnaire was used for primary data collection which was addressed to the top managers of 50 SMEs in Kosovo taken as a deliberate sample for the purpose of conducting this study by using the SPSS program 23.

Findings: It can be said with high certainty that allowing the participation of employees in the planning process, namely setting organizational objectives and goals, has had positive effects on individual and organizational performance, meaning that it has increased organizational effectiveness.

Practical Implications: This research reaffirms the fact that employee participation increases organizational effectiveness, an issue on which many other authors have done research. Also, this paper can be a source of information for the authors and other research that will be done in the future.

Originality/Value: This research article presents original work and gives an important contribution to the explanation of the topic in question through direct study in the Kosovo market, respectively in the sample of 50 SMEs.
\end{abstract}

Keywords: Employee participation, planning process, performance, organizational effectiveness.

JEL code: $L 2, M 1, M 54$

Paper type: Research article.

\footnotetext{
${ }^{1}$ University of Applied Sciences in Ferizaj, Faculty of Tourism and Environment, Ferizaj Kosovo, E-mail: pajtim.rrustemi@ushaf.net

${ }^{2}$ Corresponding author, University of Applied Sciences in Ferizaj, Faculty of Tourism and Environment, Ferizaj Kosovo, E-mail: blerina.bytyqi@ushaf.net

${ }^{3}$ University of Applied Sciences in Ferizaj, Faculty of Tourism and Environment, Department of Tourism and Hotel Management, Ferizaj, Kosovo, E-mail: alberta.tahiri@ushaf.net ${ }^{4}$ University of Applied Sciences in Ferizaj, Faculty of Tourism and Environment, Department of Tourism and Hotel Management, Ferizaj, Kosovo, E-mail: idriz.kovaci@ushaf.net
} 


\section{Introduction}

Through this paper we try to explain what impact the participation of employees in the planning process has on organizational effectiveness by giving the case of research of this phenomenon in SMEs in Kosovo. The reason for explaining this phenomenon lies in the fact that planning as the first function of management is of great importance in this process. As it is known, during this process the organizational objectives and goals are determined, and based on this fact, the relationship between the participation of employees in this process and the effects that such participation has on the performance of enterprises will be examined.

Employees can be regarded as the most powerful source of competitive advantage, which lead any firm to organizational excellence. It is worth clarifying that the employees carry their own assets to businesses they participate in, by working together, rather than as independent contributors. By this way, the workforce can create more value for the organization (Mayo, 2001). More and more organizations have empress the concept of involving its employee in running the affairs of the company (Mutai et al., 2015). Workers' involvement is a participative procedure which makes use of the whole capacity of individuals as well as to inspire staff determination for organizational achievement (Saeed, 2016).

It is worth emphasizing that when the entire workforce supports the overall strategy and the intermediate goals, firms may achieve strategic competitiveness and superior profits. Therefore, the new labor force practices should be applied as a source of contemporary competitive advantage, which enables firms to gain sustainable success for the future (Oikonomou, 2018). Participation can be defined as the employees' active involvement in planning and implementing a teamwork intervention (Hurrell, 2005). Also, when there is a high level of managerial commitment, this impacts the profits and competitiveness of companies positively. The organization of work teams has positive impacts on competitive benefits and these, in turn, on economic benefits (Oropesa-Vento et al., 2015).

Having a well-defined mission and strategic goals may not be sufficient. Business organizations must also ensure that all employees clearly understand the meaning of such objectives. Employee understanding can become instrumental, as it could allow business organizations to develop a desired type of organizational culture that will support the implementation of the firm's strategic objectives (Nowak, 2020).

According to Gitongu, Kingi, and Uzel (2016), top management needs to offer support to other staff in order to increase the stakes of the organization's performance. This support services step-up the capability of a business to involve itself in activities, behaviours and attitudes that demonstrate to back successful achievement of actions which add to employee performance. Employees have an intrinsic want of being taken care of and they need to be provided with the essential backing from management in relation to resources, endorsement, and associations in 
order to be encouraged to perform well. Therefore, leadership style is important for employee performance since leaders' actions are directed towards providing the vital task related direction and moral backing to employees. Leadership style can be evaluated on the foundation of direct and indirect outcomes achieve from the relationship between leadership and employee performance (Kabiru et al., 2018). The research questions of the study are:

1. To what extent is employee participation allowed in setting organizational objectives and goals in Kosovo SMEs, respectively in the planning process?

2. How necessary is employee participation in presenting different alternatives for solving organizational problems?

3. How does employee participation in the planning process affect organizational effectiveness?

\section{Literature Review}

The 21st century business environment is fast paced and dynamic. Organizations are under pressure due to stiff competition. As such organizations must come up with strategies that will give them a competitive edge (Butali and Njoroge, 2018). Organizations face challenges while they live in a dynamic and competitive environment. The effectiveness of a business constitutes its ability to perform a function with optimal levels of input and output (Tahsildari and Shahnaei, 2015). Business organizations identify their strategic objectives during the process of planning, which was described in literature as a sequence of logical activities aiming to define a mission, long- and short-term goals, resource allocations as well as implementation plans. Past research confirmed that the process of planning can have positive effects on various performance metrics, such as product development or profitability (Miller and Cardinal, 1994; Wolf and Floyd, 2017; Arend et al., 2017; Nowak, 2020).

Planning is the main function of management and is an ongoing process. There will be times when external factors will affect the company positively and negatively. This, in turn, can change the pre-planning process in achieving certain goals. For example, if the company's goal is to make a profit, the manager needs to determine the steps needed to achieve that goal. This can lead to higher advertising costs, to hire more experienced employees, but also to reduce unnecessary costs now, or to improve the products that are for sale (Tahiri and Kovaçi, 2017). Only after managers have developed their plans can they determine how they want to structure their organization, place their people, and establish organizational controls (Certo, and Certo, 2016).

Organizations that transfer authority and power to their employees do well as compared to the one who does not transfer (Saeed, 2016). The effectiveness of any organization is influenced greatly by human behavior. People are a resource common to all organizations (Gibson et al., 2012). Engaged employees deliver 
improved organizational and individual performance (Osborne and Hammoud, 2017). Employee involvement and workers participation can be considered two sides of a coin and have been used by different authors interchangeably. Both are complementary to each other and existence of one depends on the other. There is not much difference between the two terms. The meaning of involvement is the day-today activity of the organization and participation is an act of sharing information and decision making.

Many writers have advocated for the development of this thought of employee involvement or participation (Annakili and Jayam, 2018). Employee involvement is a process of participation and empowerment of employees to use their input towards achieving higher individual and organizational performance. Involvement refers to the employee participation in decision making and problem solving, and increased autonomy in work processes. As a result, employees are expected to be more motivated, more committed, more productive, and more satisfied with their work. Basic dimensions of involvement are, employee participation (as individuals or in teams), empowerment and self-managed teams. Employee participation is a management initiative and, as a concept means that the employees are given the opportunity to discuss issues relating to their work, to influence managerial decisions, but management reserves the right to govern (Sofijanova and ZabijakinChatleska, 2013).

Employee participation is one of the oldest areas of inquiry within the domain of organizational behavior. Scholarly attention to participation dates to the earliest works in the field (Glew et al., 1995). Literature, research, and the real working life assure the important and essential role for employees' engagement and participation which is mostly different in the real organization working life (Ali, 2017). Successful managers often embrace work-life practices and provide encouragement to employees who wish to use them. Such behaviour expresses the value the manager and company leadership place on the well-being of employees. The company stands to benefit through higher employee satisfaction, talent retention, and higher employee engagement (Robbins and Coulter, 2018).

\section{Research Methodology}

As we have mentioned, this paper was designed to clarify the phenomenon of the impact of employee participation in the planning process on organizational effectiveness. To achieve this goal the methodology of this paper is based on the quantitative method in scientific research, which means that to achieve the intended objective of this research the quantitative approach was used. Rather, a deliberate sample of 50 SMEs in Kosovo was selected, whose managers were surveyed through a structured questionnaire, mostly with closed-ended questions. It is worth mentioning that the survey was conducted with a face-to-face approach, which enabled additional information to be obtained regarding the activity of these enterprises, especially the topic discussed here. Managers were open and very 
collaborative to give higher meaning and value to this research. So, the questionnaire was the instrument that made possible the collection of primary quantitative data, which were then analysed through the program SPSS 23, and presented in tabular and graphical form. Also, in this paper are used secondary data, which have their importance in explaining the concepts and phenomena in question, as we can mention, books by domestic and foreign authors, scientific papers published in international journals, sources from the Internet etc.

\section{Results}

In this part we present the results obtained from the research conducted in 50 SMEs in Kosovo, respectively we will see the degree of allowing employee participation in the planning process (setting organizational objectives and goals) in these enterprises, the effectiveness brought by the participation of employees in solving organizational problems, the impact of this participation on organizational effectiveness and so on.

Table 1. The level of employee participation in the planning process

\begin{tabular}{|c|c|c|c|c|c|}
\hline \multicolumn{6}{|c|}{$\begin{array}{l}\text { How much is employee participation allowed in the planning process (setting } \\
\text { organizational objectives and goals) in your enterprise? }\end{array}$} \\
\hline & & Frequency & Percent & $\begin{array}{l}\text { Valid } \\
\text { Percent }\end{array}$ & $\begin{array}{l}\text { Cumulative } \\
\text { Percent }\end{array}$ \\
\hline Valid & $\begin{array}{l}\text { Not at all } \\
\text { Slightly } \\
\text { On average } \\
\text { Enough } \\
\text { A lot } \\
\text { Total }\end{array}$ & \begin{tabular}{|l|}
1 \\
2 \\
4 \\
20 \\
23 \\
$\mathbf{5 0}$ \\
\end{tabular} & $\begin{array}{l}2.0 \\
4.0 \\
8.0 \\
40.0 \\
46.0 \\
\mathbf{1 0 0 . 0} \\
\end{array}$ & \begin{tabular}{|l|}
2.0 \\
4.0 \\
8.0 \\
40.0 \\
46.0 \\
$\mathbf{1 0 0 . 0}$ \\
\end{tabular} & \begin{tabular}{|l}
2.0 \\
6.0 \\
14.0 \\
54.0 \\
100.0
\end{tabular} \\
\hline
\end{tabular}

Source: SPSS 23 output.

Table 1 shows the results of the question "How much is the participation of employees allowed in the planning process (setting organizational objectives and goals) in your enterprise?", and it turned out that out of 50 managers of surveyed enterprises $1(2 \%)$ of them stated that it does not allow employee participation in the planning process at all, $2(4 \%)$ others stated that employee participation is allowed at a very low rate, $4(8 \%)$ of them allow participation at an average rate, $20(40 \%)$ allow the participation of employees at a high level, and another 23 (46\%) do not plan almost anything without consulting their employees in advance, thus allowing their participation at very high levels. Figure 1 graphically presents the results expressed in Table 1, as a frequency and as a percentage. What we can mention here is that most managers are optimistic about the fact that the participation of employees in the process of setting organizational goals and objectives, respectively in the planning process, will undoubtedly lead to a better organizational performance, which is also the goal of each manager for his/her enterprise. 
Figure 1. The level of employee participation in the planning process

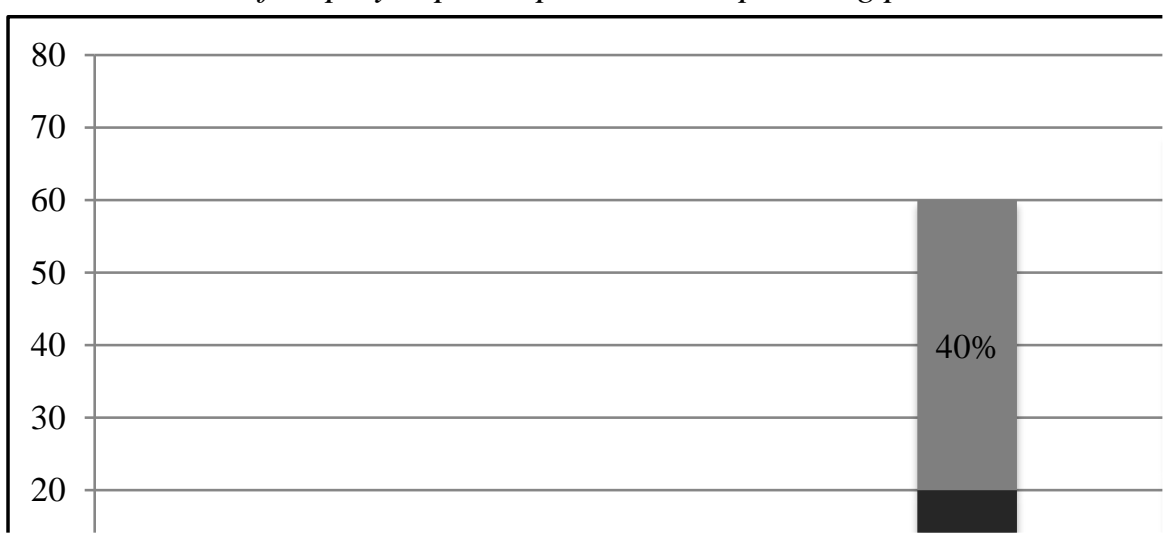

Source: Compiled by the authors based on the results of Table 1.

Table 2. Effectiveness of employee participation in solving organizational problems

\begin{tabular}{|l|l|l|l|l|}
\hline $\begin{array}{l}\text { The alternatives presented by employees positively affect the solution of } \\
\text { organizational problems? }\end{array}$ & Frequency & Percent & $\begin{array}{l}\text { Valid } \\
\text { Percent }\end{array}$ & $\begin{array}{l}\text { Cumulative } \\
\text { Percent }\end{array}$ \\
\hline \multicolumn{1}{|l|}{} & 0 & 0.0 & 0.0 & 0.0 \\
Valid Strongly disagree & 1 & 2.0 & 2.0 & 2.0 \\
Disagree & 7 & 14.0 & 14.0 & 16.0 \\
Neutral & 24 & 48.0 & 48.0 & 64.0 \\
Agree & 18 & 36.0 & 36.0 & 100.0 \\
Strongly agree & $\mathbf{5 0}$ & $\mathbf{1 0 0 . 0}$ & $\mathbf{1 0 0 . 0}$ & \\
Total &
\end{tabular}

Source: SPSS 23 output.

In Table 2 we can see the results in terms of the effectiveness of employee participation in solving the problems faced by the surveyed enterprises, and it turns out that the statements of managers regarding the fact that "Alternatives presented to employees have a positive impact on solving organizational problems?" are as follows:

- There are no managers who answered "strongly disagree";

- $1(2 \%)$ manager answered with the option "disagree";

- $7(14 \%)$ managers had a "neutral" attitude towards this issue;

- $24(48 \%)$ managers "agree" with this fact;

- $18(36 \%)$ other managers "strongly agree" that employees are the ones who can present valuable alternatives in relation to problem solving as they deal closely with certain problems that attack the day-to-day operations of enterprises. 
Figure 2. Effectiveness of employee participation in solving organizational problems

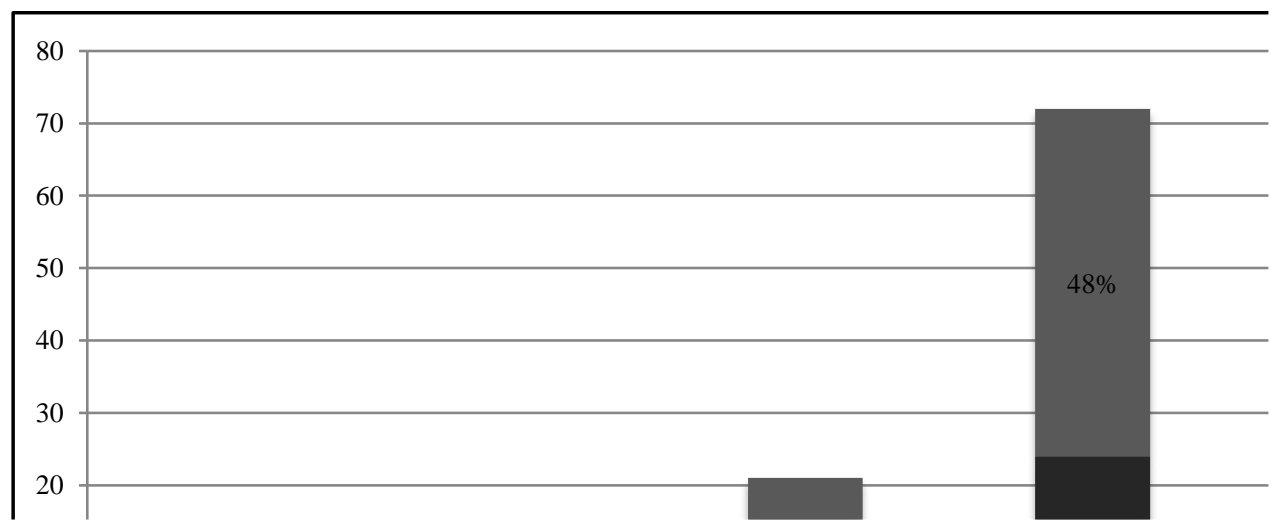

Source: Compiled by the authors based on the results of Table 2.

Figure 2 graphically presents the results of Table 2. If we make a combination between the results from Figure 1 and 2, we can say that the manager who did not allow employee participation during the planning also stated that the effectiveness of employee participation in organizational problem solving is very low. This is explained by the fact that when employee participation is not allowed, the effectiveness in solving their problems is normally very low. In other cases, we have balance in terms of employee participation and effective solution of organizational problems.

Table 3. The impact of employee participation in the planning process on organizational effectiveness

\begin{tabular}{|l|l|l|l|l|}
\hline $\begin{array}{l}\text { Employee participation in the planning process brings high organizational } \\
\text { effectiveness? }\end{array}$ & Frequency & Percent & $\begin{array}{l}\text { Valid } \\
\text { Percent }\end{array}$ & $\begin{array}{l}\text { Cumulative } \\
\text { Percent }\end{array}$ \\
\hline \multicolumn{1}{|l|}{} & 0 & 0.0 & 0.0 & 0.0 \\
Valid Strongly disagree & 0 & 0.0 & 0.0 & 0.0 \\
Disagree & 6 & 12.0 & 12.0 & 12.0 \\
Neutral & 25 & 50.0 & 50.0 & 62.0 \\
Agree & 19 & 38.0 & 38.0 & 100.0 \\
Strongly agree & $\mathbf{5 0}$ & $\mathbf{1 0 0 . 0}$ & $\mathbf{1 0 0 . 0}$ & \\
Total &
\end{tabular}

Source: SPSS 23 output.

Table 3 presents the results related to the main issue of this paper, respectively the question "How does employee participation in the planning process affects organizational effectiveness?". Regarding the statement that "Employee participation in the planning process brings high organizational effectiveness", the results that have emerged are:

- There were no such managers who stated, "strongly disagree" and "disagree"; 
- $6(12 \%)$ of the 50 managers surveyed expressed a "neutral" attitude regarding the issue discussed here;

- $25(50 \%)$ managers supported the statement that "employee participation in the planning process brings high organizational effectiveness";

- The remaining $19(38 \%)$ managers "strongly agree" with this.

Figure 3. The impact of employee participation in the planning process on organizational effectiveness

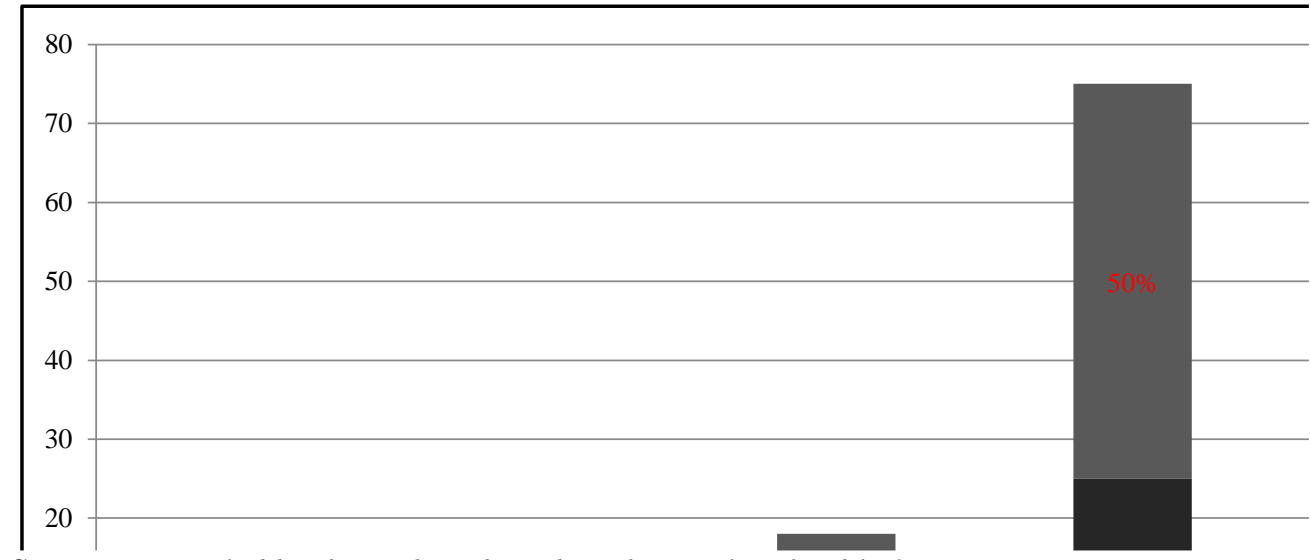

Source: Compiled by the authors based on the results of Table 3.

Figure 3, similarly to the two previous cases, graphically shows the results from Table 3, the relationship between employee participation in the planning process and organizational effectiveness, where it turned out that employee participation in the planning process brings high organizational effectiveness.

This paper, based on the results obtained, has made clear once again that employee participation in the planning process is reflected in positive impacts on organizational effectiveness. From the sample of 50 SMEs surveyed in Kosovo to explain the issue in question we have concluded that employees are the key factor which directly affects the success of the organization and that allowing their participation in the planning process (but also in other processes important for successful enterprise business) bring positive impacts on organizational performance, respectively enable the increase of organizational effectiveness.

Also, it has been found that in Kosovo enterprises, employee participation in decision-making reaches a very high level, respectively in $78 \%$ of enterprises employees participate in decision-making at a high level, $20 \%$ on the average allow their participation and only $2 \%$ of enterprises disregard employees' opinions when making organizational decisions (Tahiri et al., 2021). To be effective at work, every enterprise must work in terms of performance management of its staff. Also, performance appraisal is one of the key elements for enterprise success. Enterprises should have employee performance appraisal systems to know who is 
doing the job properly and who is not, and based on performance appraisal, bonuses should also be given to employees (Tahiri et al., 2020). The companies are encouraged to adopt employee involvement programs to enhance performance, growth and competitiveness on the regional and global market (Sofijanova and Zabijakin-Chatleska, 2013).

\section{Conclusions}

Seeing today's market which is experiencing continuous development and progress, organizations should follow the latest development trends, be as flexible as possible to consumer demands and market demands in general and offer innovations in their field to survive. Management as the most important subject of organizational governance is the one that should be oriented towards increasing organizational effectiveness through various management policy mechanisms.

One of the key factors for the success of enterprises is, without a doubt, the participation of employees in organizational processes. As seen, the emphasis in this paper was particularly on explaining the impact of employee participation in the planning process on organizational effectiveness and based on practical research of enterprises in the territory of Kosovo it became clear that employee participation in setting objectives and organizational goals, as well as their presentation of alternatives for problem solving, have positively affected the performance, both of individuals in particular and of the organization as a whole. It has been observed that most top managers of the surveyed enterprises have been proponents of allowing a high level of employee participation in the planning process, and not only.

Employees are also allowed to participate in other organizational fields and processes, of course in issues for which employees have the necessary and sufficient skills to create valuable solutions. Normally, top management is a professional organizational level that engages in the strategic processes of the organization and in these enterprises this managerial level has taken into account the contribution of their employees and has made a kind of analysis of different alternatives presented for problem solving and decision-making regarding issues which concern them during the day-to-day actions taken within the organization. What can be emphasized at the end is that the participation of employees in various organizational processes is a positive factor which affects the increase of organizational performance, respectively the increase of organizational effectiveness.

\section{References:}

Ali, A.A. 2017. Employees' participation and involvement in strategic planning process in Sudanese Wheat Flour Factories. International Journal of Economics \& Management Sciences, 6(6), 1-4. 
Annakili, P., Jayam, R. 2018. How to increase organizational commitment through employee participation. Eurasian Journal of Analytical Chemistry, 13(SP), 18-22.

Arend, R.J., Zhao, Y.L., Song, M., Im, S. 2017. Strategic planning as a complex and enabling managerial tool. Strategic Management Journal, 38(8), 1741-1752.

Butali, P., Njoroge, D. 2018. Effect of employee participation on organizational performance with organizational commitment as a moderator. International Journal of Scientific Research and Management, 06(06), 478-485.

Certo, S.C., Certo, S.T. 2016. Modern Management: Concepts \& Skills. Pearson, USA.

Gibson, J.L., Ivancevich, J.M., Donelly Jr, J.H., Konopaske, R. 2012. Organizations: Behavior, Structure, Processes. McGraw-Hill, New York.

Glew, D.J., O’leary-Kelly, A.M., Griffin, R.W., Van Fleet, D.D. 1995. Participation in organizations: A preview of the issues and proposed framework for future analysis. Journal of Management, 21(3), 395-421.

Hurrel, J. 2005. Organizational stress intervention. In: Barling, J., Kelloway, E.K., Frone, M.R. (Ed.), Handbook of work stress. SAGE, California, 623-645.

Kabiru, F.C., Matthew, T., Asborn, M. 2018. The influence of planning on the organizational performance of agricultural state-owned corporations in Kenya. International Academic Journal of Human Resource and Business Administration, 3(1), 68-80.

Mayo, A. 2001. The Human Value of the Enterprise: Valuing People as Assets Monitoring, Measuring, Managing. Nicholas Brealey Publishing, London.

Miller, C.C., Cardinal, L.B. 1994. Strategic planning and firm performance: A synthesis of more than two decades of research. Academy of Management Journal, 37(6), 16491665.

Mutai, E.K., Cheruiyot, T.K., Kirui, J.K. 2015. Impact of participatory management on employee performance: A case of MOI University. Global Journal of Commerce \& Management Perspective, 4(2), 54-59.

Nowak, R. 2020. Does employee understand of strategic objectives matter? Effects on culture and performance. Journal of Strategy and Management, 13(4), 477-493.

Oikonomou, A. 2018. Assessing the impact of employee participation on team-work performance: A way to reinforce entrepreneurship. SPOUDAI - Journal of Economic and Business, University of Piraeus, Piraeus, 68(2/3), 48-61.

Oropesa-Vento, M., Garcia-Alcaraz, J.L., Rivera, L., Monatas, D.F. 2015. Effects of management commitment and organization of work teams on the benefits of Kaizen: Planning stage. Journal of the Facultad de Minas, Universidad Nacional de Columbia - Medellin Campus, DYNA, 82(191), 76-84.

Osborne, S., Hammoud, M. 2017. Effective employee engagement in the workplace. International Journal of Applied Management and Technology, 16(1), 50-67.

Robbins, S.P., Coulter, M. 2018. Management. Pearson, USA.

Saeed, I. 2016. Employee involvement and organizational effectiveness. Pollster Journal of Academic Research, 03(01), 01-18.

Sofijanova, E., Zabijakin-Chatleska, V. 2013. Employee involvement and organizational performance: Evidence from the manufacturing sector in Republic of Macedonia. Trakia Journal of Sciences, 11(1), 31-36.

Tahiri, A., Kovaçi, I. 2017. Management in Tourism: Theoretical Managerial Approach. Research Centre, Peja.

Tahiri, A., Kovaçi, I., Krasniqi, A. 2020. Human resource management, performance management and employee performance appraisal by SME managers in Kosovo. International Journal of Economics and Business Administration, 8(4), 288-298. 
Tahiri, A., Kovaçi, I., Bushi, F., Meha, A. 2021. Decision-making and the applying of decision-making techniques in SMEs in Kosovo. Quality - Access to Success, 22(180), 64-67.

Tahsildari, A., Shahnaei, S. 2015. Enhancing organizational effectiveness by performance appraisal, training, employee participation, and job definition. European Journal of Business and Management, 7(12), 56-63.

Wolf, C., Floyd, S.W. 2017. Strategic planning research: Toward a theory-driven agenda. Journal of Management, 43(6), 1754-1788. 